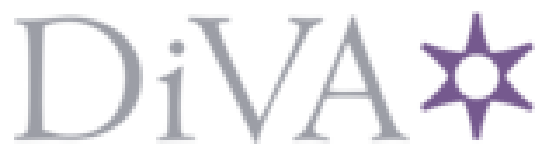

http://www.diva-portal.org

This is the published version of a paper published in .

Citation for the original published paper (version of record):

Tseronis, A. (2016)

Multimodale argumentatie: Bruggen slaan tussen argumentatieleer en multimodale analyse

Tijdschrift voor Taalbeheersing, 38(1): 1-26

https://doi.org/10.5117/TVT2016.1.TSER

Access to the published version may require subscription.

N.B. When citing this work, cite the original published paper.

Permanent link to this version:

http://urn.kb.se/resolve?urn=urn:nbn:se:oru:diva-70100 


\title{
Multimodale argumentatie: bruggen slaan tussen argumentatieleer en multimodale analyse
}

\author{
Assimakis Tseronis
}

TT 38 (1): 1-26

DOI: 10.5117/TVT2016.1.TSER

\begin{abstract}
Multimodal argumentation: Building bridges between argumentation theory and multimodal analysis

Since the end of the 90s there has been an increasing interest in the analysis of images and in their interplay with written language. Even though images, especially when used in advertisements, have already been studied within rhetorical approaches to communication and visual studies, there still lacks a systematic account of their contribution to the way standpoints are put forward and argumentation is advanced. At the same time, within the field of discourse analysis interest has been expressed in the analysis of visual and other non-verbal elements of communication. Nevertheless, no special attention has been paid within this field to those communicative situations where the support of a standpoint with arguments and the acceptability of the argumentation are at stake. In order to be able to analyse the various aspects of multimodal documents on their merits and to account for their argumentative relevance it is necessary to build bridges between argumentation theory and multimodal analysis. This paper discusses critically the current state of affairs regarding the analysis of multimodal documents from an argumentation studies perspective and argues for a systematic study of the interplay of the verbal and the visual modes within the framework of Pragma-dialectics. Three print advertisements are analysed in order to illustrate the merits of such an approach to the argumentative analysis of multimodal documents.
\end{abstract}

Keywords: multimodal argumentation, Pragma-dialectics, advertisements, visual argumentation, visual rhetoric 


\section{$1 \quad$ Inleiding}

De afgelopen twintig jaar hebben discours-analytici grote stappen gezet in het analyseren van teksten die naast verbale ook visuele en auditieve elementen bevatten (Kress \& van Leeuwen, 1996). ${ }^{1}$ In de argumentatietheorie hebben Birdsell en Groarke in 1996 voor het eerst gepleit voor een uitbreiding van argumentatieonderzoek in dezelfde richting (zie ook Groarke, 1996). Hoewel hun voorstel aanvankelijk op kritiek stuitte (zie Fleming, 1996; Johnson, 2003), zijn er tegenwoordig steeds meer argumentatie-onderzoekers die de argumentatieve rol van beelden in bepaalde genres bestuderen, zoals in reclame, tv-spots en posters (Roque, 2009; Kjeldsen, 2012; van den Hoven \& Yang, 2013) ${ }^{2}$. Zij noemen hun onderzoeksobject 'visuele argumentatie'.

Uit de analyses van visuele argumentatie die in de literatuur te vinden zijn, blijkt dat zowel de verbale als de visuele modaliteit van de desbetreffende teksten van belang zijn voor de argumentatieve interpretatie ervan. Een multimodale analyse van argumentatief discours waarin van meerdere modaliteiten gebruik wordt gemaakt, wordt door de meeste auteurs echter niet consequent doorgevoerd. De consequentie van een dergelijk perspectief op argumentatieanalyse zou immers moeten zijn dat in het proces van betekenisoverdracht de visuele en de verbale modus hetzelfde gewicht krijgen toegekend, dus dat de verbale modus niet als belangrijker wordt gezien dan de visuele modus. Een andere consequentie van een multimodaal perspectief is dat er systematisch aandacht moet worden besteed aan zowel vorm- en stijlelementen als aan de inhoud van de verbale en visuele elementen in een tekst.

In dit artikel pleit ik voor een multimodale benadering van argumentatieve teksten waarin woord en beeld worden gecombineerd. Een multimodale benadering houdt in dat in de analyse van het discours zowel de verbale als de visuele modus worden bestudeerd, en met name de interactie tussen deze twee modi. ${ }^{3} \mathrm{Ik}$ begin met een kritische bespreking van de belangrijkste literatuur over visuele argumentatie. Duidelijk zal worden dat zowel degenen die zich met visuele argumentatie bezighouden als hun critici uitgaan van de presuppositie dat er een strikte taakverdeling bestaat tussen de verbale en de visuele modus. Betoogd zal worden dat de door beide groepen gemaakte tegenstelling tussen verbale en visuele argumentatie niet houdbaar is (paragraaf 2). In plaats van het gangbare perspectief op argumentatie (Blair, 2012a), waarin de verbale modus wordt beschouwd als bepalend voor de karakterisering van argumentatie, stel ik, op basis van inzichten ontleend aan de discourse analyse, een multimodaal perspectief 
op argumentatieanalyse voor (paragraaf 3 ). Ik zal laten zien dat de pragmadialectische benadering van argumentatie een heel geschikt theoretisch kader biedt voor de toepassing van een multimodaal perspectief (paragraaf 4). Tot slot zal ik mijn benadering toelichten door enkele advertenties te analyseren (paragraaf 5 ).

\section{Vooronderstellingen van argumentatietheoretici over visuele argumentatie}

\subsection{Argumentatie is een talige aangelegenheid}

Birdsell en Groarkes (1996) constatering dat in alledaagse (ook argumentatieve) communicatie zowel verbale als non-verbale elementen een rol spelen, bracht hen tot de conclusie dat een betoog niet altijd louter verbaal van aard hoeft te zijn. ${ }^{4}$ In een reactie op deze stelling betoogden Fleming (1996) en Johnson (2003) echter vast te willen blijven houden de verbale karakterisering van de notie 'argument'. Taal speelt volgens deze auteurs een fundamentele rol, niet alleen in het argumenteren zelf, maar ook in de analyse van argumentatie. Terwijl beelden ambigu en context-afhankelijk zijn, zou taal juist precieze en abstracte concepten kunnen beschrijven. Bovendien maakt taal het mogelijk de waarheidswaarde van proposities vast te stellen, terwijl beelden willekeurig geïnterpreteerd kunnen worden. In deze zienswijze wordt een argument als een product beschouwd dat uit premissen bestaat die een conclusie ondersteunen. De nadruk ligt dan op de formele aspecten van de linguïstische code, en betekenis is dan identiek aan de formele en lexicale eigenschappen van de afzonderlijke elementen die een zin of een tekst vormen. In deze visie is er dus geen aandacht voor de functionele en context-afhankelijke aspecten van betekenis.

Fleming (1996) beweert dat het onmogelijk is om in een beeld premissen en een conclusie te onderscheiden. Doordat beelden als geheel begrepen worden, zouden deze onderdelen van een argument niet waargenomen kunnen worden. Taal zou dan ook onontbeerlijk zijn om de conceptuele structuur van het argument te kunnen vatten. Beeld zou alleen maar als ondersteuning kunnen dienen van verbaal uitgedrukte elementen, met als doel de acceptatie van de premissen te bevorderen. Het zal duidelijk zijn dat Fleming zich hier uitsluitend richt op de inhoudelijke betekenis van beelden. Beelden kunnen echter ook een functionele betekenis hebben als de rol van de context in ogenschouw wordt genomen, en zo'n functie kan binnen zo'n context ook argumentatief zijn (zie Novitz, 1977). Bovendien makt Fleming geen onderscheid tussen inhoud en vorm van een beeld, 
terwijl dat twee verschillende bronnen van betekenis zijn. Al met al negeert Fleming de mogelijkheden die beeldmakers hebben kijkers te sturen met kleur, compositie en vormgebruik (zie Van den Broek et al., 2010).

Ook Johnson (2003) benadrukt in zijn kritiek dat argumentatie inherent talig is, en dat deze taligheid in de argumentatietheorie tot op de dag van vandaag de concepten en de methodes voor de analyse en evaluatie van argumentatie heeft bepaald. Hij stelt dat er een fundamentele asymmetrie bestaat tussen verbale en visuele argumenten. De interpretatie van visuele argumenten gebeurt immers in taal, maar de interpretatie van verbale argumenten wordt niet met beeld gedaan: visuele argumenten kunnen wel op de een of andere manier in verbale proposities weergegeven worden, maar er is geen duidelijke, conventionele manier waarop een verbaal argument in beeld gebracht kan worden. Omdat de vertaling van beeldelementen naar proposities volgens hem sterk afhankelijk is van 'verbal reasoning and verbal expressions of reasoning' (2003, p. 3), zou er sprake zijn van een innerlijke tegenspraak in het begrip 'visueel argument'. Met deze kritiek op visuele argumentatie wekt Johnson de indruk dat de problemen die een rol kunnen spelen bij de argumentatieve reconstructie van beeldelementen bij uitstek kenmerkend zouden zijn voor visuele argumentatie. Wat hij daarbij over het hoofd ziet is dat problemen met interpretatie en context-afhankelijkheid zich ook bij verbale argumentatie voordoen.

In tegenstelling tot Fleming en Johnson ziet Blair (2012a, p. 218) geen principiële theoretische problemen rondom de erkenning van visuele argumenten:

While visual arguments are possible, they seem not to be widespread. More significantly, they seem not to constitute a radically different kind of argument from verbal ones. $[\ldots]$ There is no reason to ignore or overlook visual arguments. However, their existence presents no theoretical challenge to the standard sorts of verbal argument analysis.

De analyse en evaluatie van een argument, ongeacht de modus waarmee het naar voren is gebracht, is volgens Blair altijd op een verbale reconstructie gebaseerd. Daarom zouden visuele argumenten volgens hem niet radicaal anders zijn dan verbale argumenten. In deze visie wordt de methode van argumentatie-analyse echter verward met het object van de analyse. Dat talige middelen moeten worden gebruikt om het resultaat van een argumentatieve analyse weer te geven, betekent niet automatisch dat men bij het analyseren en beoordelen van argumentatie uitsluitend een beroep mag doen op talige criteria, zoals Roque (2009, p. 7) terecht stelt: 
The fact that language has been and still is fundamental for proposing concepts in order to understand and analyse how argumentation works does not imply that the different argumentative tools that we constantly use are verbal by nature.

\subsection{Een strikte taakverdeling tussen de verbale en de visuele modus}

Zowel Fleming en Johnson als de meer gematigde Blair zijn door Groarke (2007, p. 139) bekritiseerd vanwege hun 'zeer beperkte visie' op argumentatie, gebaseerd op de 'dogma's van verbalisme en reductionisme'. Volgens het dogma van verbalisme bestaan argumenten uit proposities en zijn volledig verbale uitingen de beste, zo niet de enige manier om de elementen van een argument weer te geven. Volgens het dogma van reductionisme moeten beelden naar verbale zinnen vertaald kunnen worden om ze als argumenten te kunnen analyseren en evalueren. Beide dogma's hebben te maken met wat Roque (2009, p. 2) het 'linguïstische imperialisme' in de argumentatieleer noemt. Tegenover deze 'verbale' opvatting van argumentatie stellen onderzoekers zoals Groarke en Roque een 'visuele' opvatting, die evenveel bestaansrecht zou hebben.

Het maken van een onderscheid tussen 'verbale' argumenten aan de ene kant en 'visuele' aan de andere brengt echter een aantal problemen met zich mee. Als eerste zorgt het onderscheid voor een eenzijdige taakverdeling tussen deze twee modi, waarbij de verbale modus voor het uiten van een standpunt zou zorgen, terwijl de visuele modus de ondersteuning van dit standpunt zou betreffen, de argumentatie dus. Deze taakverdeling is voorondersteld in een aantal studies naar visuele argumentatie. Dove (2012) is bijvoorbeeld op zoek naar de precisering van de argumentatieve functie van visuele elementen, zoals afbeeldingen (met name foto's) en figuren gebruikt in argumentatieve communicatie, zowel in het wetenschappelijke als in het reclamedomein. Volgens hem fungeren beelden niet als een op zichzelf staand argument of een op zichzelf staande premisse, maar vormen ze de ondersteuning ('evidence') van de verbale premisse. Door op deze manier naar het visuele aspect te kijken, en te veronderstellen dat visuele argumentatie altijd expliciete verbale elementen nodig heeft die de argumentatieve interpretatie sturen, ontkent Dove dat beelden een zelfstandige argumentatieve rol kunnen vervullen.

Ook de typologieën van non-verbale elementen in argumentatieve communicatie die zijn onderscheiden door Groarke \& Tindale (2013) als Roque (2012), lijken gebaseerd te zijn op de veronderstelling dat beelden slechts 
een ondersteunende functie hebben. Volgens Groarke \& Tindale (2013, pp. 143-158) kunnen er vier soorten non-verbale argumenten onderscheiden worden: argument flags (waar het visuele element wordt gebruikt om aandacht op het verbale argument te trekken), non-verbal demonstrations (waar het visuele element als ondersteuning/bewijs voor de conclusie dient), visual symbols (waar het visuele element in het teken van een idee staat) en visual metaphors (waar het visuele element wordt gebruikt om een associatie tussen twee ideeën vast te stellen). De auteurs beschouwen de non-verbal demonstrations als 'the most basic way in which non-verbal elements function as argument components' (p. 145). Uit deze karakterisering kan worden afgeleid dat zij visuele elementen in argumentatieve communicatie enkel als ondersteuning beschouwen van een verbaal standpunt. Hetzelfde geldt voor Roque (2012) en zijn classificatie van visuele argumenten. Hij onderscheidt de volgende categorieën: visual flag (waar het beeld uitsluitend dient om de aandacht van de kijker te trekken), parallel argument (waar zowel het beeld als de verbale tekst hetzelfde argument naar voren brengen), joint argument (waar het beeld met de verbale tekst gecombineerd moet worden om het argument te reconstrueren), en contrasting argument (waar het beeld gecontrasteerd wordt met de verbale tekst). In het geval van een joint argument merkt Roque op dat de conclusie van het argument meestal in de tekst wordt gegeven, terwijl het beeld dient als bewijsmateriaal.

De hierboven veronderstelde taakverdeling tussen de verbale en de visuele modus, waarin een eenzijdige relatie bestaat tussen beelden en premissen aan de ene kant en taal en conclusies aan de andere kant, kan worden verklaard doordat de genoemde auteurs een formele benadering van argumentatie aanhangen, waarin argumentatie wordt beschouwd als een product dat uit premissen en een conclusie bestaat. Visuele elementen kunnen in zo'n opvatting van argumentatie slechts een beperkt rol spelen doordat hieraan uitsluitend een retorische en emotieopwekkende rol wordt toegekend. Blair (2012b, p. 271) bijvoorbeeld concludeert dat de functie van beelden in argumentatieve communicatie meer te maken heeft met hun retorische overtuigingskracht, die de onbewuste en irrationele kant van de kijker aanspreekt, dan met de logische en dialectische dimensie van argumenteren: 'The visual element in visual arguments is most significantly a rhetorical dimension, rather than logical or dialectical'.

Naast de hierboven besproken beperkte visie op de rol van de visuele elementen in argumentatief discours, brengt de door Groarke en Roque veronderstelde taakverdeling tussen verbale en visuele elementen nog een ander probleem met zich mee. Dit is het probleem dat in de analyse 
van argumentatieve teksten waarin verbale en visuele elementen worden gecombineerd, er nauwelijks aandacht is voor de vorm en de stijl van de visuele elementen. Als de rol van beelden in argumentatieve communicatie uitsluitend door hun inhoudelijke betekenis wordt bepaald, is er geen aandacht voor keuzes die te maken hebben met onder andere compositie, layout, en kleurenpalet. Hoewel Roque (2009) zich op een theoretisch niveau wel bewust lijkt te zijn van de betekenis die ontstaat door de manier waarop het betekende door de betekenaar is weergegeven, concentreren zijn analyses zich toch steeds vooral op wat afgebeeld is in plaats van op de manier waarop dit afgebeeld is (zie Roque, 2012). In dit licht is het ook problematisch dat, hoewel verschillende auteurs expliciet aangeven hoe belangrijk de context is bij het interpreteren van de beelden, in geen van de gepresenteerde analyses systematisch rekening wordt gehouden met het specifieke genre waarin beeld en tekst samen worden gebruikt om argumenten naar voren te brengen. Zo identificeren Birdsell en Groarke (1996, p. 6) weliswaar drie lagen van de context die men nodig heeft om visuele argumenten te analyseren: de directe visuele context, de directe verbale context, en de algemene beeldcultuur. In hun analyses laten ze echter niet zien hoe informatie uit elk van deze lagen de voorgestelde reconstructie van het argument rechtvaardigt. Uitzonderingen in dit verband zijn overigens Van den Hoven en Yang (2013) en Kjeldsen (2012). Van den Hoven en Yang (2013) besteden in hun analyse van een tv-fragment uit het nieuwsjournaal wel aandacht aan de retorische situatie, dat wil zeggen, aan het publiek dat op een bepaald moment aangesproken wordt, aan de doelen die de beeldmaker wil bereiken en aan de beperkingen van het specifieke genre van communicatie. Ook Kjeldsen (2012) besteedt aandacht aan de context en de beperkingen van het genre in het kader van zijn analyses van het gebruik van beelden in politieke cartoons en commerciële of politieke advertenties.

In tegenstelling tot wat in de literatuur over visuele argumentatie verondersteld wordt over de relatie tussen de visuele en verbale aspecten van een bepaald discours, komt het in de praktijk vaak voor dat in argumentatief en/of retorisch georiënteerde teksten visuele elementen onlosmakelijk verbonden zijn met verbale elementen. In deze gevallen zorgt alleen de interactie tussen deze twee elementen voor een interpretatie van hun betekenis. 'Visueel' en 'verbaal' verwijzen dus niet naar twee concepties van argumentatie, maar naar twee mogelijke modi die gecombineerd kunnen worden in een argumentatieve tekst (voorbeelden van andere modi zijn muziek en geluid). De betekenis van een tekst die beeld met woord combineert ligt dan ook niet zozeer in de opsomming van de betekenissen van de 
afzonderlijke elementen, maar juist in de manier waarop deze gecombineerd zijn. In de afgelopen twee decennia is deze constatering het uitgangspunt geworden in het snel groeiende gebied van multimodale analyse. Studies in dit gebied (o.a. Jewitt, 20ogb; Bateman, 2014) bieden inzichten voor een systematische bestudering van de eigenschappen van de verschillende non-verbale modi die voorkomen in alledaagse argumentatieve communicatie. In de volgende paragraaf zal hier nader op worden ingegaan.

\section{Naar een multimodale benadering van argumentatief discours}

Auteurs zoals Groarke, Roque, Dove, Kjeldsen en Van den Hoven hebben het pad geëffend voor de analyse van argumentatieve teksten die meer dan één modus combineren. Deze auteurs hebben echter niet volledig de consequenties getrokken die een multimodaal perspectief op de analyse en evaluatie van argumentatie met zich meebrengt. Hoewel Birdsell en Groarkes (1996) roep om aandacht voor de non-verbale aspecten in argumentatieve communicatie parallel liep met het voorstel voor de multimodale discours analyse van Kress en van Leeuwen (1996), hebben zij geen kennis kunnen nemen van deze ideeën omdat zij het bestaan er niet van kenden. Deze en andere ideeën over multimodale discourse analyse zijn echter wel degelijk van belang voor het hanteren van een multimodaal perspectief binnen de argumentatietheorie.

Voortbouwend op een opvatting van taal als sociaal-semiotische interactie, zoals bepleit door Halliday (1978), hebben Kress en van Leeuwen een poging gedaan een systematisch overzicht te geven van de opties die een beeldmaker heeft om betekenis over te brengen, te weten: kleur, perspectief, compositie en typografie. Daarbij kennen ze ook een rol toe aan de maatschappelijke, culturele en historische omstandigheden waarin beelden geproduceerd en geïnterpreteerd worden. Volgens het multimodale perspectief op de analyse van discours (zie ook Bateman, 2014) heeft de verbale modus geen bijzondere voorrang op de visuele modus of andere non-verbale modi. Een analyse in het multimodale perspectief richt zich zowel op de inhoud als op de vorm van elke afzonderlijke modus, en op de combinaties daarvan, zoals Jewitt (2009a, p. 1) schrijft: 
The starting point of multimodality is to extend the social interpretation of language and its meanings to the whole range of representational and communicational modes or semiotic resources for making meaning that are employed in a culture - such as image, writing, gesture, gaze, speech, posture.

Volgens een multimodaal perspectief op communicatie vormen beeld en taal afzonderlijke, complexe systemen van betekenis die een aantal verschillende gebruiksmogelijkheden (affordances) kennen, afhankelijk van de aard en het materiaal van elke verschillende modus (Kress, 2009; Stöckl, 2004). Zo biedt bewegend beeld andere mogelijkheden dan statisch beeld: het ene heeft met sequentie en tijdsverloop te maken, terwijl het andere met ruimte- en plaatsverhoudingen te maken heeft.

Aandacht voor de specifieke eisen van de (mogelijke combinaties van) modi (zie Martinec \& Salway, 2005) is niet alleen nuttig voor de analyse van communicatie in het algemeen, maar ook voor de analyse van argumentatieve communicatie in het bijzonder. De verschillende modi die bijdragen aan betekenis in communicatie in het algemeen zouden namelijk ook een rol kunnen spelen in de productie en interpretatie van argumenten. In de huidige benadering van multimodale analyse is er echter geen expliciete aandacht voor de argumentatieve functie van de verschillende modi in teksten die gericht zijn op het overtuigen van een publiek. Het werk van Bateman en zijn collega's om criteria vast te stellen voor een effectief ontwerp (effective design) van multimodale teksten is weliswaar een interessante uitzondering, maar ook hij legt geen nadruk op specifieke argumentatieve contexten (Bateman, 2008; Delin \& Bateman, 2002).

Binnen de argumentatietheorie kunnen Willards (1981) non-discursiveness thesis en Gilberts (1994) begrip van modi van argumenteren als voorlopers van een multimodaal perspectief op argumentatie beschouwd worden. Willard stelt dat als men argumentatie als interactie opvat, erkend moet worden dat argumenteren niet enkel talige communicatie is: 'arguments ${ }_{1}$ consist both of discursive and non-discursive symbols and both must be grappled with if we are to understand their meanings' (1981, p. 194). Naar aanleiding van Willards positie stelt Gilbert (1994) voor argumentatie te beschouwen als 'multi-modal argumentation'. In tegenstelling tot de algemeen aanvaarde definitie van 'modus' zoals gehanteerd in multimodale analyse (zie Kress, 2009), verwijst Gilbert met zijn begrip 'modus' echter niet naar de semiotische middelen die worden gebruikt om een argument naar voren te brengen in communicatie. Volgens hem zijn er ten minste nog drie modi naast de logische modus te onderscheiden, gebaseerd op verschillende normen die de interpretatie en evaluatie van een 
argument mede bepalen. Dit zijn de emotionele modus (die op de emoties ingaat), de viscerale modus (die met aanraken en lichaamstaal te maken heeft), en de kiscerale modus (van het Japanse woord 'ki' dat met intuïtie en spirituele kracht te maken heeft). Hoewel Gilbert zelf niet zozeer geïnteresseerd is in visuele argumentatie, draagt zijn 'multi-modale' opvatting wel bij aan een benadering van argumentatie waarin het verbale aspect niet meer centraal staat. Zoals de voorbeelden die hij in zijn artikel bespreekt voor elke modus laten zien, is een argument niet uitsluitend te reconstrueren vanuit de taal of de woorden die door de deelnemers worden gebruikt. Gilberts visie is hier dus van belang omdat deze het primaat van de verbale aard van argumentatie in twijfel trekt.

Een argument is geen taalkundige categorie die gedefinieerd wordt door de semantiek en syntaxis van de taal. Bij argumentatie gaat het om het gebruik van woorden of andere semiotische middelen in een specifieke context. Bepalend voor het herkennen van de argumentatieve functie van deze verbale of non-verbale elementen is dat ze gebruikt worden in een context van een (potentieel) meningsverschil met als doel een opponent te overtuigen van de aanvaardbaarheid van een positie. In argumentatieve communicatie als interactive enterprise volgens Gilbert (of als social interaction in Willards woorden) worden de elementen van een argument dan ook niet rechtstreeks gereconstrueerd aan de hand van de lexicale betekenis van de woorden en hun constructie in zinnen. Reconstructie gebeurt op grond van pragmatische overwegingen gebaseerd op afleidingsprocessen die in gang worden gezet door het gekozen woord en beeld in een specifieke argumentatieve situatie, waarin een publiek wordt aangesproken met het doel om het van de aanvaardbaarheid van een standpunt te overtuigen.

Verbale en non-verbale elementen, afzonderlijk of gecombineerd, kunnen dus direct of indirect bijdragen aan een argumentatieve discussie. Zoals door de meeste voorbeelden die besproken zijn door Dove, Groarke en Roque geillustreerd wordt, kunnen beelden inderdaad de premissen ter verdediging van de (verbale) conclusie van een argument weergeven. Maar met een beeld kan ook het standpunt naar voren worden gebracht, terwijl de argumenten gereconstrueerd kunnen worden op basis van kennis van de context en kennis van het specifieke genre van communicatie. Immers, niet alleen de inhoud van een beeld kan bepalend zijn voor de interpretatie van een argument, maar ook de visuele stijl, zoals die tot uiting komt in gekozen vorm, kleur, toon, textuur, kadrering, etc. (zie Dondis, 1973; Van den Broek et al., 2010), en het gebruik van technieken als herhaling, symmetrie, contrast etc. De non-verbale elementen kunnen informatie toevoegen die belangrijk is voor het vaststellen van de argumentatieve situatie, de 
manier waarop het publiek aangesproken wordt, en de manier waarop de argumenten met elkaar verbonden moeten worden om het standpunt te verdedigen. Zo heeft Kjeldsen $(2007,2012)$ laten zien dat visuele metaforen en andere figuren niet alleen een decoratieve rol spelen, maar ook sturend zijn in de argumentatieve interpretatie van advertenties. Op een vergelijkbare manier heeft Feteris (2012) standpunten en argumentatie gereconstrueerd op basis van de visuele metaforen in politieke cartoons. ${ }^{5}$

In plaats van 'visuele argumentatie' te conceptualiseren in oppositie tot of als uitbreiding van 'verbale argumentatie', doe ik het voorstel om eerst te onderkennen dat communicatie waarin argumentatie plaatsvindt, zich kenmerkt door multimodaliteit. Dat wil zeggen dat in alledaagse communicatie teksten worden geproduceerd en geïnterpreteerd die verbale en non-verbale modi combineren om een boodschap over te brengen (zie Kress, 2009). Naast de modus taal kunnen verschillende andere semiotische modi worden gebruikt, zoals beeld, lichaamstaal en geluid. Tegelijkertijd kan het medium waarin verschillende modi door en met elkaar worden gebruikt ook variëren, namelijk van papier en webpagina's tot televisie en film. ${ }^{6}$ Het is mogelijk dat de deelnemende partijen (de auteur en zijn publiek) via deze modi en communicatiemedia een overtuigingspoging doen om een (potentieel) meningsverschil op te lossen. Dan is er sprake van multimodale argumentatie, dat wil zeggen van een argumentatieve activiteit waarin meer dan één modus gebruikt wordt om een discours te produceren waarin een taalgebruiker argumenten naar voren brengt om een andere partij van de aanvaardbaarheid van zijn of haar standpunt te overtuigen. In de volgende paragraaf zal ik betogen dat de pragma-dialectische argumentatietheorie een geschikt kader biedt waarin deze zienswijze geïntegreerd kan worden.

\section{Een pragma-dialectisch kader voor de argumentatieve analyse van multimodaal discours}

Zoals in de vorige paragraaf duidelijk is geworden, wordt binnen een multimodale benadering van argumentatie niet alleen systematisch aandacht besteed aan de eigenschappen van de verschillende modi en hun onderlinge combinaties, maar ook aan de situationele en institutionele context waarbinnen de argumentatieve activiteit plaatsvindt. Toepassing van een multimodale analyse op argumentatief discours vereist evenwel een theoretisch kader vanuit de argumentatieleer, waarin plaats wordt geboden aan zowel de verbale als non-verbale elementen die een rol spelen in de argu- 
mentatie. De pragma-dialectische opvatting van argumentatie (Van Eemeren, 2010, 2012) biedt een goed uitgangspunt voor het verkennen van de argumentatieve functies van visuele en andere non-verbale elementen.

In de pragma-dialectiek wordt argumentatie beschouwd als onderdeel van een discussieprocedure die ten doel heeft de houdbaarheid van standpunten te testen (Van Eemeren, 2010, p. 31). Van Eemeren en Grootendorst (2004, p. 2) onderkennen dat: 'In practice, argumentation can also be partly, or even wholly, non-verbal.' Dit betekent dat de modus waarin een argumentatieve zet wordt gedaan in principe geen belemmering hoeft te zijn voor het identificeren van zijn bijdrage aan een argumentatieve discussie. De enige voorwaarde om als zet geanalyseerd te kunnen worden is dat voor de analyse en evaluatie van de argumentatie alle proposities door verbale middelen geëxpliciteerd kunnen worden.

De concepten en instrumenten die in de pragma-dialectiek zijn ontwikkeld voor de analyse en evaluatie van argumentatief discours hebben betrekking op de taken die in elk stadium van de procedure voor het oplossen van een meningsverschil uitgevoerd moeten worden (dat wil zeggen: in elk van de discussiefasen). ${ }^{7}$ Naast het naar voren brengen van een standpunt en het poneren van argumenten ter verdediging van dat standpunt, worden er in de verschillende stadia van een kritische discussie namelijk ook andere typen zetten gedaan. Die zetten, die zowel door de protagonist van een standpunt als de antagonist kunnen worden gedaan, hebben onder andere te maken met het uiten van twijfel, het vaststellen van uitgangspunten, het geven van een definitie of verklaring, het stellen van een kritische vraag of het reageren op een tegenargument. Dit betekent dat het vaststellen van de betekenis van visuele elementen (voortvloeiend uit hun inhoud of stijl) zich niet uitsluitend hoeft te richten op het reconstrueren van standpunten en argumenten.

In de pragma-dialectiek wordt ook aandacht besteed aan de effectiviteit van de discussiezetten die in de verschillende discussiefasen gedaan kunnen worden. Dit is het gevolg van de uitbreiding van het dialectisch kader met inzichten uit de klassieke en moderne retorica onder de notie 'strategisch manoeuvreren'. Vanuit het perspectief van strategisch manoeuvreren bestudeert men het argumentatieve discours als het resultaat van keuzes gemaakt door de discussiant (schrijver, spreker of beeldmaker) met het oog op het nastreven van effectiviteit en het handhaven van redelijkheid. Van Eemeren (2012, p. 124) schrijft hierover: 
Effectiviteit betekent in retorische zin het tot stand brengen van het resultaat dat met de betreffende argumentatieve zet beoogd wordt. Redelijkheid kan in dialectische zin gedefinieerd worden als voldoen aan de normen die besloten liggen in de regels voor het voeren van een kritische discussie.

Vanuit dit perspectief worden non-verbale en verbale discussie-elementen geanalyseerd als keuzes die de discussiant heeft gemaakt uit de verschillende zetten die op een bepaald moment in een discussie mogelijk zijn (topische keuze), de manier waarop het auditorium geadresseerd kan worden (adaptatie aan publiek) en de manier waarop verschillende presentatiemogelijkheden (o.a. stilistische aspecten) benut worden om zowel het retorische als het dialectische doel na te streven (presentatiekeuzes). ${ }^{8}$

Verder opent het pragma-dialectische begrip argumentatieve actietypen (Van Eemeren \& Houtlosser, 2006) de deur naar de systematische bestudering van de rol van de communicatieve situatie en de institutionele context waarin een bepaald argumentatief discours plaatsvindt. Het betrekken van de conventies van de gebruikscontext in de analyse van het argumentatieve discours maakt het mogelijk om de beperkingen en de mogelijkheden te bestuderen die een specifiek actietype biedt voor de productie en interpretatie van argumentatie. Zo speelt de kennis van het genre en van de argumentatieve situatie niet alleen een rol bij de analyse van verbale argumentatie, maar ook bij het vaststellen van de argumentatieve relevantie van non-verbale elementen (zie hieronder de analyses van de advertenties).

Een argumentatietheorie zoals de pragma-dialectiek verschaft een specifiek kader van verwante begrippen waarbinnen de combinatie van verbale en visuele modi geïnterpreteerd kan worden in de specifieke context (het argumentatieve actietype) waarin een poging wordt gedaan tot het overtuigen van een redelijke opponent door middel van argumenten. Dat elk actietype beperkingen en mogelijkheden met zich meebrengt wat betreft de discussiezetten die kunnen worden gedaan, betekent dat het gebruik van verschillende modi en de combinatie ervan geïnterpreteerd kunnen worden in het licht van de rol die ze spelen in de desbetreffende argumentatieve context (zie Feteris et al., 2011). ${ }^{9}$ Hieruit vloeit logischerwijs voort dat niet uitsluitend bestudeerd zal worden wat afgebeeld is maar ook hoe dit afgebeeld wordt, en hoe het publiek wordt gestuurd in haar interpretatie van het afgebeelde. In de volgende paragraaf zal worden geschetst wat dit concreet inhoudt voor de analyse van advertenties. 


\section{Argumentatieve analyse van multimodaal discours: voorbeelden uit advertenties}

Een advertentie kan in pragma-dialectische termen worden geanalyseerd als een poging om een niet-gemengd verschil van mening tussen de reclamemaker (namens de producent), als protagonist, en de beoogde koper, als antagonist, op te lossen (zie Van Eemeren, 2010, p. 235). Gezien het promotionele doel van dit genre kan het hoofdstandpunt van een advertentie worden opgevat als een prescriptief standpunt, namelijk 'Koop product/service X'. Meestal blijft zo'n standpunt impliciet. Wel expliciet zijn de positieve eigenschappen en kwaliteiten van het geadverteerde product - expliciet in de zin dat ze gereconstrueerd kunnen worden uit zowel de verbale als de visuele elementen in de advertentie. Deze eigenschappen functioneren als een of meer beoordelende propositie(s) ter ondersteuning van het hoofdstandpunt (zie ook Pollaroli \& Rocci, 2015). Vanuit een argumentatief perspectief is een advertentie dus niet slechts een simpele uiting van een mening of oordeel over een product, maar een poging om het publiek, dat nog geen of een andere mening heeft, aan te sporen een product of een service te kopen door het ervan te overtuigen dat dit een goed product is of dat er positieve gevolgen verbonden zijn aan de aankoop van het product. ${ }^{10}$ In de woorden van Ripley (2008, p. 517):

An ad, [however,] is not just someone expressing an opinion about a product. An ad is not just someone saying that s/he believes the product is good. An ad is someone saying that the product is good because someone else obviously either does not think it is good or has not yet realized that the product is good and needs to be convinced of the goodness (or appropriateness, affordability, etc.).

In onderstaande analyses beschouw ik advertenties als multimodale teksten en zal ik ze, vanuit het multimodale perspectief dat ik eerder heb beschreven, analyseren als bijdragen aan een argumentatieve discussie. Een pragma-dialectische argumentatieve reconstructie heeft als doel:

- het identificeren van standpunt(en) waarover verschil van mening ontstaat,

- het achterhalen van de argumenten ter verdediging van de standpunten,

- het expliciteren van de structuur van deze argumenten en hun relatie met het standpunt (de argumentatiestructuur), 
- het beschrijven van de strategische manoeuvres die worden gebruikt door elk van de partijen. ${ }^{11}$

Voor een volledige reconstructie zijn zowel de inhoud als de vorm van belang van alle modi die gebruikt worden in de tekst. Verder is het zaak om rekening te houden met het genre waarin de communicatie gesitueerd is en de daarbij behorende achtergrondkennis. In de voorbeelden die ik hieronder zal bespreken, kunnen het standpunt en de argumenten gereconstrueerd worden uit de interactie tussen de verbale en de visuele modus. In het eerste voorbeeld vormt vooral het visuele contrast, versterkt door de parallelle structuur, het aanknopingspunt voor de reconstructie van de argumentatie; in het tweede voorbeeld is het de visuele manipulatie van een bestaande zwart-wit foto die de belangrijkste indicator is voor de argumentatieve reconstructie; in het derde is het vooral de layout van het gehele beeld en de manier waarop tekst en beeld gestructureerd zijn.

\subsection{Chux keukenhandschoenen}

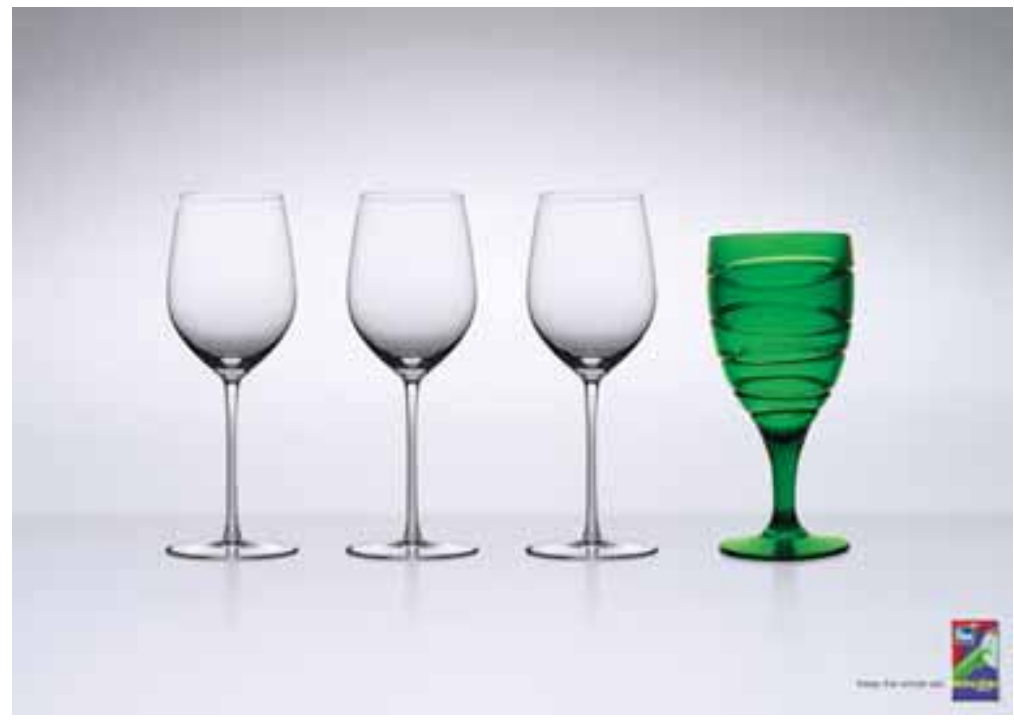

Figuur 1

Figuur 1 is een advertentie voor Chux keukenhandschoenen. Deze toont vier glazen op een rij; de eerste drie zijn allemaal identiek en de vierde en laatste wijkt daarvan af: die is groen en heeft een andere vorm. In de rechter benedenhoek staat, naast een kleine afbeelding van de verpakking van 'Chux extra grip' de tekst: 'Keep the whole set'. Dit is de enige verbale 
uiting in deze reclame. Noch de tekst, noch het beeld kunnen afzonderlijk van elkaar begrepen worden of op zichzelf een aanwijzing vormen voor de analyse van het standpunt of de argumenten. De tekst 'Keep the whole set' verklaart niet wat er in beeld staat, en het beeld kan ook niet dienen ter illustratie van deze tekst. Wel is het duidelijk dat het hier over een advertentie van keukenhandschoenen gaat.

Welke argumenten kunnen worden gereconstrueerd ter verdediging van het impliciete standpunt 'Koop Chux keukenhandschoenen'? Als we beroep doen op onze kennis van de wereld en het afwassen, kunnen we de conclusie trekken dat het beeld het resultaat toont van een ongelukje tijdens de afwas. De aansporing 'Keep the whole set' wordt dus gecontrasteerd met de afbeelding van wat het resultaat zou kunnen zijn als iemand zonder de geadverteerde handschoenen de afwas doet. Men loopt dan immers het risico te blijven zitten met een onvolledige set glazen. Dit risico wordt verbeeld door het glas dat er anders uitziet: korter, niet elegant, groen, niet transparant, dik. Door dit glas samen in een strakke, symmetrische compositie te zetten met de glazen die wel bij elkaar horen, wordt het verschil juist onderstreept. ${ }^{12}$ De beeldmaker had het ongewenste resultaat van het afwassen zonder Chux handschoenen ook kunnen laten zien door een asymmetrische compositie te gebruiken van slechts drie glazen op een rij met de vierde plek leeg. Maar in dat geval was de onwenselijkheid van het resultaat niet zo duidelijk overgekomen. Door te laten zien hoe een incomplete set glazen eruit ziet, nodigt de beeldmaker de kijker uit om de gevolgen te overwegen die kunnen ontstaan wanneer men bij het afwassen geen gebruik maakt van handschoenen 'met grip'.

Op grond van bovenstaande overwegingen kan de argumentatie in deze advertentie als volgt gereconstrueerd worden:

1. Koop Chux handschoenen [impliciet standpunt], want

1.1a Chux handschoenen bieden extra grip [gereconstrueerd uit de tekst], en

1.1b Extra grip is nodig tijdens het afwassen [gereconstrueerd uit het afwassen scenario], want

1.1b.1a Extra grip voorkomt ongelukken tijdens het afwassen [gereconstrueerd uit het afwassen scenario], en

1.1b.1b Jij wilt zulke ongelukken voorkomen [gereconstrueerd uit verwachtingen over de wensen van het publiek], want

1.1b.1b.1 Je wilt geen incomplete set serviesgoed [gereconstrueerd uit verwachtingen over de wensen van het publiek], want

1.1b.1b.1.1 Een incomplete set is lelijk [gereconstrueerd uit het beeld] 
In deze reconstructie wordt het standpunt met twee nevengeschikte argumenten (1.1a en 1.1b) ondersteund, die het standpunt gezamenlijk ondersteunen. Het tweede nevengeschikte argument (1.1b) wordt op zijn beurt ook weer door twee nevengeschikte argumenten ondersteund. Het tweede nevengeschikte argument van dit niveau in de argumentatiestructuur (1.1b.1b) wordt vervolgens nog door twee niveaus onderschikkende argumentatie ondersteund..$^{13}$

\subsection{Music is what matters}

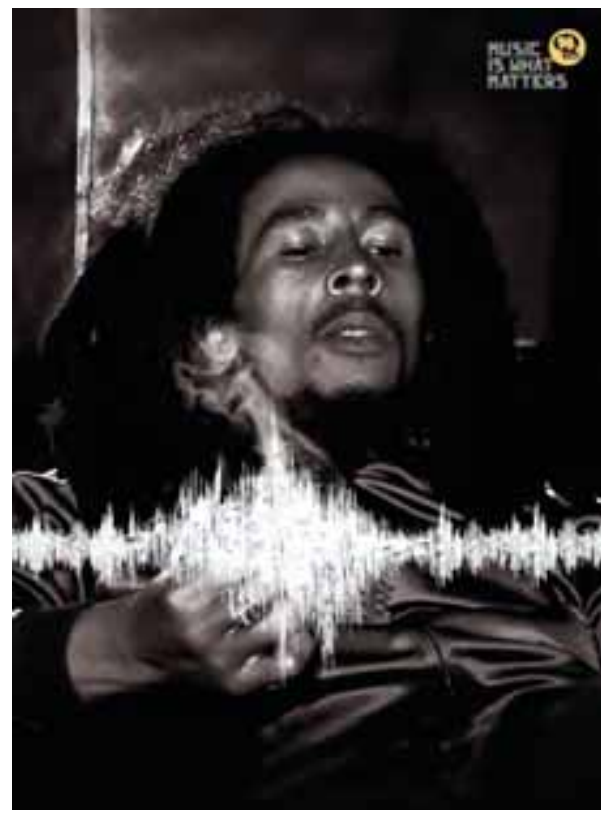

Figuur 2

Figuur 2 is een advertentie gemaakt voor een radiostation in Brazilië. Om publiek voor het station te werven wordt een bestaande zwart-wit foto van de zanger Bob Marley gebruikt. De zanger ligt op een bank, zich niet bewust van de camera. In zijn vingers houdt hij een sigaret, waarschijnlijk een joint. De zwart-wit foto is bedekt met een dikke, witte geluidsgolf die precies de plek verbergt van Marleys vingers-met-joint. In de linker bovenhoek van de poster staat het logo van het radiostation en de tekst 'Music is what matters'.

Het standpunt dat aan deze advertentie ten grondslag ligt is 'Luister naar 98fm radio'. Opnieuw ligt de argumentatieve interpretatie van de advertentie noch alleen in de verbale tekst, noch alleen in wat er afgebeeld 
wordt, maar in de combinatie van deze twee modi. De tekst zelf legt de nadruk op muziek als het enige dat ertoe doet, maar laat verder niet weten waar de discussie überhaupt over gaat. Wanneer alleen het beeld in ogenschouw zou worden genomen, zou het afgebeelde misschien opgevat kunnen worden als een afwijzing van het (ongewenste) gedrag van Marley. Als de tekst echter in samenhang met het beeld wordt geïnterpreteerd, wordt het duidelijk dat het hier gaat over de spanning tussen de muziek van de artiest en zijn eigen persoonlijke gewoonten en eigenaardigheden. De muziek die het geadverteerde station uitzendt, wordt met puur muziek gerelateerde criteria gekozen en niet aan de hand van de al dan niet discutabele gewoonten van de artiesten.

De witte, dikke geluidsgolf lijkt op het conventionele gebruik van het zwarte balkje, een kruis of een rode streep om iets onwenselijks te verbergen of af te wijzen. ${ }^{14}$ Dit zou kunnen betekenen dat het station het gedrag van Marley afkeurt. Maar op basis van algemene kennis over de muziekwereld - een aantal van de artiesten heeft een levensstijl die anders is dan die van de normale mens - weten we dat geen enkel radiostation ooit reclame zou maken met een moreel afkeurend oordeel over de artiesten van wie zij muziek draaien. Het is daarom niet mogelijk om de argumentatie in deze advertentie te reconstrueren als 'want we geven geen oordeel over het leven van de artiesten'. Juist het feit dat de horizontale lijn een geluidsgolf verbeeldt en het feit dat deze de hand van Marley slechts gedeeltelijk verbergt, suggereert dat het radiostation Marleys voorkeuren niet per se afkeurt. Integendeel, het station laat op een creatieve manier weten dat het muziek uitzendt van artiesten die zowel door hun muziek als door hun afwijkende gedrag populair zijn geworden..$^{15}$ Maar tegelijkertijd beschermt het station zich ook tegen mogelijke kritiek dat het dit soort gedrag zou goedkeuren. De argumentatie kan daarom als volgt gereconstrueerd:

1. Luister naar $98 \mathrm{fm}$ radio [impliciet standpunt], want

1.1a We spelen alleen maar goede muziek af [gereconstrueerd uit de tekst], en

1.1b We wijzen enfants terribles niet af [gereconstrueerd uit de visuele manipulatie van de foto] 


\subsection{The Guardian}
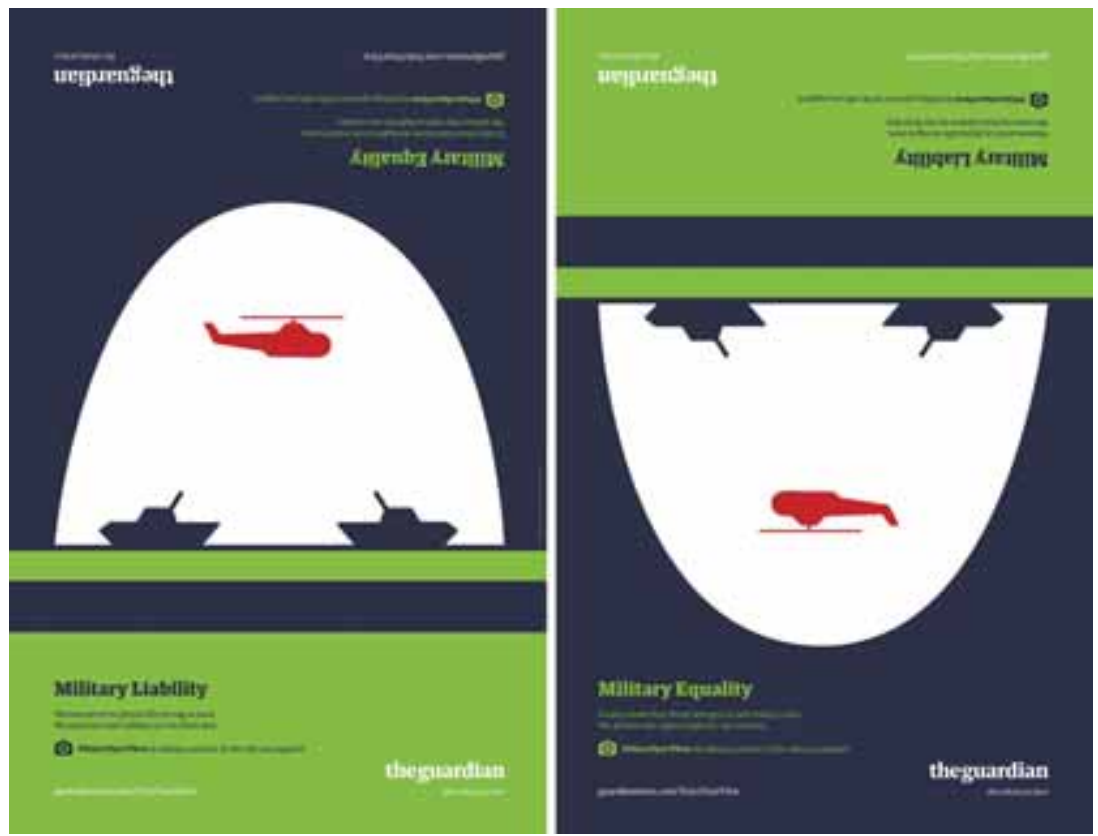

Figuur 3

In 2013 lanceerde de Britse krant The Guardian in de VS een campagne om de kenmerkende redactionele stem en een experiment met open journalism te promoten. In de campagne werden van vier vurig bediscussieerde thema's in de VS steeds beide kanten van het debat (letterlijk) in beeld gebracht, namelijk van de internetprivacy, de beperking van vuurwapens, vrouwen in het leger, en het gebruik van condooms in de porno-industrie. ${ }^{16}$ Figuur 3 toont beide helften van de poster over vrouwen in het leger. Aan de ene kant zien we twee grijze tanks op een groene ondergrond, gericht op een rode helikopter tegen een witte halve-ovaal op de achtergrond. De tekst op deze kant van de poster luidt:

\section{Military Liability}

Women aren't as physically strong as men.

We need our best soldiers on the front line.

Voice Your View by taking a picture of the side you support.

guardiannews.com/VoiceYourView

theguardian

the whole picture 
Op de andere helft veranderen de tanks en de helikopter in de ogen en rode lippen van een vrouw die een helm draagt. De tekst die hier te lezen is, luidt:

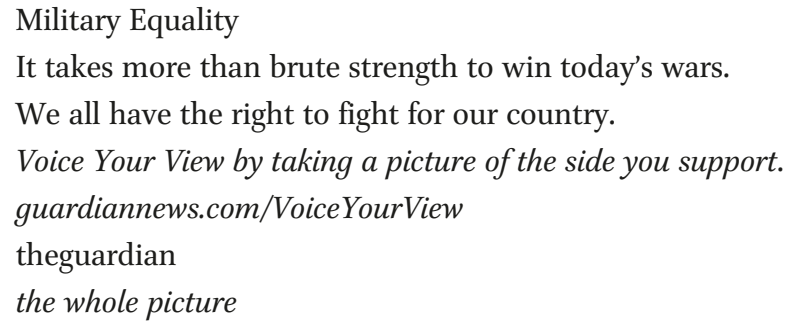

Hoewel deze tekst wel argumenten voor en tegen de plaatsing van vrouwen in het leger bevat, biedt hij eigenlijk geen direct argument ter verdediging van het standpunt 'Koop The Guardian', behalve misschien de kreet 'the whole picture', maar geïsoleerd van het beeld maakt deze uiting onvoldoende duidelijk wat die argumentatie dan zou zijn. Het beeld zou op het eerste gezicht slechts als achtergrond voor de tekst beschouwd kunnen worden met een visualisatie van het slagveld of van een vrouwelijke militair. Maar als de twee modi met elkaar gecombineerd worden en aandacht wordt besteed aan de keuzes voor de layout van de poster, dan valt ten eerste op te merken dat in deze campagne de mogelijkheid wordt uitgebuit om twee kanten van dezelfde poster te bekijken door deze handmatig of in gedachten om te draaien. De twee teksten worden zo op de pagina gezet dat de kijker wordt uitgenodigd het beeld om te draaien om de ene of de andere kant te kunnen lezen. Dit is een keuze die niks met de inhoud van de verbale modus te maken heeft maar wel met de visuele manipulatie van de vorm van de tekst door layout en compositie. Tegelijkertijd wordt, wat het beeld zelf betreft, ingespeeld op 'negatieve ruimte' om uit dezelfde schematische vormen en platte kleuren twee verschillende beelden te laten zien, afhankelijk van het perspectief van waaruit iemand naar het beeld kijkt. ${ }^{17}$ In die zin laat de poster precies het beeld zien dat de kreet 'the whole picture' beweert. Dit argument wordt door de layout en de ambiguïteit van het beeld verbeeld, namelijk dat The Guardian beide kanten van het verhaal laat zien. De argumentatie zou daarom als volgt gereconstrueerd kunnen worden:

1. Koop The Guardian [impliciet standpunt], want

1.1 The Guardian geeft inzicht in het gehele beeld [gereconstrueerd uit de tekst in combinatie met het beeld], want 
1.1.1 The Guardian laat beide kanten van de belangrijkste sociale thema's zien [gereconstrueerd uit de layout van de poster]

\section{Conclusie}

In dit artikel heb ik de (groeiende) literatuur op het gebied van 'visuele argumentatie' kritisch besproken en heb ik de tekortkomingen laten zien van de veronderstelling die aan die literatuur ten grondslag ligt, namelijk dat er een conceptuele tegenstelling bestaat tussen een 'verbaal argument' en een 'visueel argument'. Ik heb een voorstel gedaan voor een multimodaal perspectief op de analyse van argumentatief discours, waarbij staat de gedachte centraal dat communicatie in het algemeen en argumentatie in het bijzonder mogelijk wordt gemaakt door een proces van betekenisoverdracht die meer wel dan niet op een combinatie van modi berust. Vanuit dit perspectief worden visuele en andere non-verbale modi bestudeerd als gelijkwaardig aan de verbale modus en wordt ervan uitgegaan dat zowel inhoudelijke als vormaspecten van de verschillende modi (en de combinaties ervan) betekenis kunnen geven. Van de bestaande benaderingen binnen de argumentatietheorie hanteert de pragma-dialectiek een ruime opvatting van argumentatie, namelijk als een overtuigingspoging die binnen een specifieke gebruikscontext plaatsvindt. Een dergelijke blik op argumentatie biedt plaats aan zowel de verbale als de non-verbale elementen die een rol kunnen spelen in het proces van het overtuigen van een opponent van de aanvaardbaarheid van een bepaald standpunt.

Om te illustreren wat een multimodale analyse van argumentatief discours binnen de pragma-dialectische benadering inhoudt, heb ik een drietal advertenties geanalyseerd. In deze analyses is rekening gehouden met de specifieke eigenschappen van iedere modus en met hun interactie, maar ook met achtergrondkennis en informatie over het genre. De analyses laten zien dat er, in tegenstelling tot wat er tot nu toe in de literatuur over visuele argumentatie wordt beweerd, geen sprake is van een strikte taakverdeling tussen de verbale en de visuele modus waarbij het standpunt en de hoofdargumentatie verbaal naar voren gebracht zouden worden en beelden zouden dienen als ondersteuning van de expliciet naar voren gebrachte argumenten.

Uiteraard is verder onderzoek vereist op zowel theoretisch als analytisch niveau. Met name is het van belang inzicht te krijgen in de beperkingen die de context (in de vorm van het specifieke genre en actietype) kunnen leveren in de 'vertaling' van non-verbale elementen naar (verbale) 
proposities. Daarnaast dient de deugdelijkheid van bestaande classificaties van tekst-beeld-combinaties uit multimodale analyse (zie Martinec \& Salway, 2005; Bateman, 2014) en hun compatibiliteit met concepten uit de argumentatietheorie nader onderzocht te worden. In dit verband is het belangrijk meer case studies uit verschillende media uit te voeren, om zo de mogelijke combinaties van verschillende modi in argumentatieve communicatie beter te kunnen beschrijven. ${ }^{18}$ Empirisch onderzoek is vooral ook verreist in verband met vragen betreffende de manier waarop het publiek tot een argumentatieve interpretatie van multimodale teksten komt en de mate waarin voorgestelde reconstructies van de multimodale argumentatie overeenkomen met de interpretatie ervan door het publiek. Tot slot: uiteraard is het doel van een argumentatieve reconstructie een beoordeling van de deugdelijkheid en van de effectiviteit van de argumenten te kunnen geven. Als we een duidelijker idee hebben van de argumentatieve en retorische functies van beeld- en tekstcombinaties, en er een systematische methode is om te kunnen bepalen aan welke gebondenheden een beeldmaker in een concreet geval gehouden kan worden, kunnen we ook met de evaluatie van multimodale argumentatie beginnen.

\section{Noten}

1. Delen van dit artikel werden gepresenteerd als vrijdagmiddaglezing bij de onderzoeksgroep Taalbeheersing, Argumentatietheorie en Retorica van de UvA, en tijdens de $10^{\mathrm{e}}$ Conferentie van de Ontario Society for the Study of Argumentation in Windsor, Canada. Ik ben veel dank verschuldigd aan Jet Willers voor de tijd die ze heeft besteed om met mij over statische en bewegende beelden in film en televisie te praten, en voor haar nauwkeurige verzorging van mijn tekst. Ik wil ook Ton van Haaften en Henrike Jansen bedanken voor de eindredactie van mijn tekst.

2. Zie ook het themanummer getiteld "Visual and Multimodal Argumentation" (red. Kjeldsen, 2015).

3. Om deze reden is de terminologie 'visuele argumentatie' mijns inziens dan ook ongeschikt (want te beperkt) om dit type discours te beschrijven.

4. Interessant om op te merken is hier dat al in de jaren zeventig moderne retorici discussieerden over de vraag of visuele artefacten ook door retorici bestudeerd mogen worden (zie Foss, 2004).

5. In haar studie beperkt Feteris zich (2012; zie ook Feteris et al., 2011) tot een visuele troop, namelijk een visuele metafoor, en ze analyseert deze als een presentatietechniek die gebruikt wordt om indirect kritiek op politici in politieke cartoons over te brengen. Mijn doelstelling verschilt van die van Feteris doordat de integratie van inzichten uit de argumentatietheorie en multimodale analyse centraal staat, terwijl Feteris specifiek ingaat op de manier waarop specifieke visuele figuren geanalyseerd moeten worden.

6. Zie Stöckl (2004) voor een discussie over het onderscheid tussen de verschillende modi en de mogelijke combinaties tussen de verbale en de visuele modus. 
7. Volgens de pragma-dialectiek worden de volgende vier stadia in het ideaalmodel van een kritische discussie onderscheiden: de confrontatiefase, de openingsfase, de argumentatiefase en de afsluitingsfase (Van Eemeren \& Snoeck Henkemans, 2011).

8. De mate waarin in de argumentatieve werkelijkheid non-verbale modi bijdragen aan de retorische doelen van de discussianten maar het dialectische doel van de discussie schenden, vormt een interessante empirische vraag die uitgebreide en systematische analyse van case studies vereist.

9. Zie noot 5 .

10. Of advertenties meestal argumenten gebruiken die niet direct relevant voor het geadverteerde product zijn, is een empirische vraag die geen directe gevolgen heeft voor de argumentatieve analyse van dit genre (zie ook Slade, 2003; Kjeldsen, 2012).

11. In de pragma-dialectiek heeft de reconstructie van een argumentatieve discussie tot doel een beoordeling van de discussiezetten mogelijk te maken. Het beoordelen van de gereconstrueerde argumentatie valt buiten de doelstelling van mijn artikel, maar vragen betreffende de evaluatie van de bijdrage van beelden en andere non-verbale modi in argumentatieve communicatie dienen uiteraard verder onderzocht te worden.

12. Maes en Schilperoord (2009) beschouwen de vormgevingselementen die de nabijheid en/of symmetrie van de verschillende elementen in een beeld benadrukken als tegenhanger van verbale schema's. 'Object grouping' beschouwen zij dus als een visueel schema. In de bespreking van een ander beeld uit dezelfde Chux campagne - een incomplete set theekopjes - concluderen ze dat de perceptuele incompatibiliteit van het laatste object in de rij de boodschap van de advertentie benadrukt, namelijk het ongewenste resultaat van het niet gebruik maken van het geadverteerde product.

13. Zie Van Eemeren \& Snoeck Henkemans (2011, hoofdstuk 5) over de argumentatiestructuur van het betoog.

14. Zie Giora et al. (2009) voor visuele negation markers als rode kruizen en rode diagonale strepen, en Oversteegen \& Schilperoord (2014) over de mogelijkheid dat beelden zelf (zonder het gebruik van additionele tekens van waarschuwing of afwijzing) een ontkennende interpretatie kunnen uitlokken.

15. In de andere twee beelden uit dezelfde campagne staan Keith Richards met opgestoken middelvinger, en Amy Winehouse die bier drinkt tijdens haar optreden.

16. De website van de campagne is http://voiceyourview.guardiannews.com/ en op http:// www.theguardian.com/guardian-us-press-office/advertising-campaign-voice-your-view is meer informatie over de campagne te vinden.

17. 'Negatieve ruimte' verwijst naar het gebied rondom het hoofdonderwerp van een beeld (zie Van den Broek et al. (2010). Vanuit de ene kant gezien is de witte, halve ovaal de negatieve ruimte waarbinnen de twee tanks en de helikopter te onderscheiden zijn. Vanuit de andere kant gezien wordt de witte, halve ovaal het hoofdonderwerp van het beeld, namelijk het gezicht van een vrouw.

18. Voor een argumentatieve analyse van de covers van nieuwsbladen zie Tseronis (2015a), voor een argumentatieve analyse van documentaires zie Tseronis (2015b) en Tseronis et al. (2015). 


\section{Literatuur}

Bateman, J. (2008). Multimodality and Genre: A Foundation for the Systematic Analysis of Multimodal Documents. Basingstoke: Palgrave Macmillan.

Bateman, J. (2014). Text and Image. A Critical Introduction to the Visual/verbal Divide. London: Routledge.

Birdsell, D., \& Groarke, L. (1996). Toward a theory of visual argument. Argumentation and Advocacy, 33, 1-10.

Blair, A. (2012a). The possibility and actuality of visual arguments. In A. Blair (red.), Groundwork in the Theory of Argumentation (pp. 205-223). Amsterdam: Springer.

Blair, A. (2012b). The rhetoric of visual arguments. In A. Blair (red.), Groundwork in the Theory of Argumentation, (pp. 261-279). Amsterdam: Springer.

Delin, J., \& Bateman, J. (2002). Describing and critiquing multimodal documents. Document Design, 3, 140-155.

Dondis, D. (1974). A Primer of Visual Literacy. Cambridge: MIT Press.

Dove, I. (2012). On images as evidence and arguments. In F.H. van Eemeren \& B. Garssen (red.), Topical Themes in Argumentation Theory: Twenty Exploratory Studies (pp. 223-238). Amsterdam: Springer.

Eemeren, F.H. van (2010). Strategic Maneuvering in Argumentative Discourse. Extending the Pragma-dialectical Theory of Argumentation. Amsterdam: John Benjamins.

Eemeren, F.H. van (2012). Bien étonnés... Hoe de dialectische en de retorische benadering van argumentatie samenkwamen. Tijdschrift voor Taalbeheersing, 34, 115-134.

Eemeren, F.H. van, \& Grootendorst, R. (2004). A Systematic Theory of Argumentation. The Pragma-dialectical Approach. Cambridge: Cambridge University Press.

Eemeren, F.H. van, \& Houtlosser, P. (2006). Strategisch manoeuvreren, het model van een kritische discussie en conventionele actietypen. Tijdschrift voor Taalbeheersing, 28, 1-14.

Eemeren, F.H. van, \& Snoeck Henkemans, F. (2011). Argumentatie. Inleiding in het analyseren, beoordelen en houden van betogen (vierde druk). Amsterdam: Noordhoff Uitgevers.

Feteris, E. (2012). Strategisch manoeuvreren in politieke cartoons met een visuele scenariometafoor. Tijdschrift voor Taalbeheersing, 34, 199-212.

Feteris, E., Groarke, L., \& Plug, J. (2011). Strategic maneuvering with visual arguments in political cartoons: A pragma-dialectical analysis of the use of topoi that are based on common cultural heritage. In E. Feteris, B. Garssen \& F. Snoeck Henkemans (red.), Keeping in Touch with Pragma-dialectics: In Honor of Frans H. van Eemeren (pp. 59-74). Amsterdam: John Benjamins.

Fleming, D. (1996). Can pictures be arguments? Argumentation and Advocacy, 33, 11-22.

Foss, S. (2004). Theory of visual rhetoric. In K. Smith, S. Moriarty G. Barbatsis, \& K. Kenney (red.), Handbook of Visual Communication: Theory, Methods and Media (pp. 141-152). London: Routledge.

Gilbert, M. (1994). Multi-modal argumentation. Philosophy of the Social Sciences, 24, 159-177.

Giora, R., Heruti, V., Metuki, N., \& Fein, O. (2009). "When we say no we mean no": Interpreting negation in vision and language. Journal of Pragmatics, 41, 2222-2239.

Groarke, L. (1996). Logic, art and argument. Informal Logic, 18, 105-129.

Groarke, L. (2007). Beyond words. Two dogmas of informal logic. In H. Hansen \& R. Pinto (red.), Reason Reclaimed: Essays in Honor of J. Anthony Blair and Ralph H. Johnson (pp. 135-151). Newport News: Vale Press.

Groarke, L., \& Tindale, C. (2013). Good Reasoning Matters. A Constructive Approach to Critical Thinking (vijfde druk). Canada: Oxford University Press. 
Halliday, M. (1978). Language as Social Semiotic: The Social Interpretation of Language and Meaning. London: Arnold.

Jewitt, C. (2009a). Introduction: Handbook rationale, scope and structure. In C. Jewitt (red.), The Routledge Handbook of Multimodal Analysis (pp. 1-7). London: Routledge.

Jewitt, C. (red.) (2009b). The Routledge Handbook of Multimodal Analysis. London: Routledge.

Johnson, R. (2003). Why visual arguments aren't arguments. In A. Blair, D. Farr, H. Hansen, R. Johnson \& C. Tindale (red.), Informal Logic @25: Proceedings of the Windsor Conference (pp. 113). CD-ROM. Windsor, ON: OSSA.

Kjeldsen, J. (2007). Visual argumentation in Scandinavian political advertising: A cognitive, contextual, and reception oriented approach. Argumentation and Advocacy, 43, 124-132.

Kjeldsen, J. (2012). Pictorial argumentation in advertising: Visual tropes and figures as a way of creating visual argumentation. In F.H. van Eemeren \& B. Garssen (red.), Topical Themes in Argumentation Theory: Twenty Exploratory Studies (pp. 239-255). Amsterdam: Springer.

Kjeldsen, J. (red.) (2015). Visual and Multimodal Argumentation. Special issue. Argumentation, 29.

Kress, G., \& van Leeuwen, T. (1996). Reading Images: The Grammar of Visual Design. London: Routledge.

Kress, G. (2009). What is mode? In C. Jewitt (red.), The Routledge Handbook of Multimodal Analysis (pp. 54-67). London: Routledge.

Maes, A., \& Schilperoord, J. (2009). Schemes and tropes in visual communication. In J. Renkema (red.), Discourse of Course. An Overview of Research in Discourse Studies (pp. 67-78). Amsterdam: Benjamins.

Martinec, R., \& Salway, A. (2005). A system for image-text relations in new (and old) media. Visual Communication, 4, 337-371.

Novitz, D. (1977). Pictures and their Use in Communication. The Hague: Martinus Nijhoff.

Oversteegen, E., \& Schilperoord, J. (2014). Can pictures say no or not? Negation and denial in the visual mode. Journal of Pragmatics, 67, 89-106.

Pollaroli, C., \& Rocci, A. (2015). The argumentative relevance of pictorial and multimodal metaphor in advertising. Journal of Argumentation in Context, 4, 158-199.

Ripley, L. (2008). Argumentation theorists argue that an ad is an argument. Argumentation, 22, 507-519.

Roque, G. (2009). What is visual in visual argumentation?. In J. Ritola (red.), Argument Cultures: Proceedings of OSSA og (pp. 1-9). Windsor, ON: OSSA.

Roque, G. (2012). Visual argumentation: A further reappraisal. In F.H. van Eemeren \& B. Garssen (red.), Topical Themes in Argumentation Theory: Twenty Exploratory Studies (pp. 273-288). Amsterdam: Springer.

Slade, C. (2003). Seeing reasons: Visual argumentation in advertisements. Argumentation, 17, 145160.

Stöckl, H. (2004). In between modes. Language and image in printed media. In E. Ventola, C. Cassily \& M. Kaltenbacher (red.), Perspectives on Multimodality (pp. 9-3o). Amsterdam: Benjamins.

Tseronis, A. (2015a). Multimodal argumentation in news magazine covers: A case study of front covers putting Greece on the spot of the European economic crisis. Discourse, Media and Context, $7,18-27$.

Tseronis, A. (2015b). Documentary film as multimodal argumentation: Arguing audio-visually about the 2008 financial crisis. In J. Wildfeuer (red.), Building Bridges for Multimodal Research. International Perspectives on Theories and Practices of Multimodal Analysis (pp. 325343). Frankfurt am Main: Peter Lang.

Tseronis, A., Forceville, C., \& Grannetia, M. (2015). The argumentative role of visual metaphor and visual antithesis in 'fly-on-the-wall' documentary. In B. Garssen, D. Godden, D. Mitchell \& F. 
Snoeck Henkemans (red.), Proceedings of the 8th International Conference on Argumentation, CD-Rom (pp. 1380-1395). Amsterdam: SicSat.

Van den Broek, J., Koetsenruijter, W., de Jong, J., \& Smit, L. (2010). Beeldtaal. Perspectieven voor makers en gebruikers. Den Haag: Boom Lemma.

Van den Hoven, P., \& Yang, Y. (2013). The argumentative reconstruction of multimodal discourse, taking the ABC coverage of President Hu Jintao's visit to the USA as an example. Argumentation, 27, 403-424.

Willard, C. (1981). The status of the non-discursiveness thesis. Journal of the American Forensic Association, 17, 190-214.

\section{Over de auteur}

Assimakis Tseronis is in 2009 aan de Universiteit Leiden gepromoveerd. Tussen 2009 en 2012 werkte hij als post doc-onderzoeker bij het CNRS in Parijs. Sinds april 2012 is hij werkzaam als universitair docent bij de afdeling Mediastudies van de Universiteit van Amsterdam. Hij voert zijn onderzoek naar de argumentatieve analyse van multimodale teksten uit in samenwerking met de capaciteitsgroep Taalbeheersing, Argumentatietheorie en Retorica van de Universiteit van Amsterdam, waar hij ook colleges geeft. 